\title{
Effects of uncertainty in upper-stem diameter information on tree volume estimates
}

\author{
James A. Westfall ${ }^{1} \cdot$ Ronald E. McRoberts ${ }^{2} \cdot$ Philip J. Radtke $^{3} \cdot$ Aaron R. Weiskittel $^{4}$
}

Received: 7 April 2016/Revised: 18 July 2016/Accepted: 5 August 2016/Published online: 23 August 2016

(C) Springer-Verlag Berlin Heidelberg (outside the USA) 2016

\begin{abstract}
Almost all relevant data in forestry databases arise from either field measurement or model prediction. In either case, these values have some amount of uncertainty that is often overlooked when doing analyses. In this study, the uncertainty associated with both measured and predicted data was quantified for upper-stem diameter at $5.27 \mathrm{~m}$. This uncertainty was propagated through a tree taper model into predictions of individual-tree volume. The effects of uncertainty on individual-tree volume predictions and population estimates of total volume were assessed. Generally, when little or no systematic measurement deviation was present, less uncertainty was associated with field-measured diameters compared to model predictions. However, diameters predicted from a model were preferred when systematic deviations in field measurement exceeded approximately $0.2 \mathrm{~cm}$. Comparisons of results obtained from an alternative taper model showed that more precise
\end{abstract}

Communicated by Arne Nothdurft.

James A. Westfall

jameswestfall@fs.fed.us

Ronald E. McRoberts

rmcroberts@fs.fed.us

Philip J. Radtke

pradtke@vt.edu

Aaron R. Weiskittel

aaron.weiskittel@umit.maine.edu

1 U.S. Forest Service, Northern Research Station, Newtown Square, PA, USA

2 U.S. Forest Service, Northern Research Station, St. Paul, MN, USA

3 Virginia Tech, Blacksburg, VA, USA

4 University of Maine, Orono, ME, USA estimates of population totals might be obtained without upper-stem diameter information. Upper-stem diameter information increases the prediction accuracy of individual-tree volume, and thus, models using this information may be preferable in applications such as timber sales containing high-value trees. Due to the various factors that influence measurement and modeling uncertainty, foresters are encouraged to make similar evaluations in the context of their specific activities.

Keywords Error propagation - Measurement variability . Taper model $\cdot$ Quality assurance $\cdot$ Forest inventory

\section{Introduction}

Estimation of merchantable tree volume has long been a key reason for conducting forest inventories. Because tree volume is essentially impossible to directly measure in the field, statistical models are employed to estimate the volume using more easily measured tree characteristics. In many cases, diameter at breast height (dbh) and an upperstem measurement are used as model predictor variables (Scott 1981; Jordan et al. 2005). While accurate measurements of dbh are easily attained, reliable upper-stem measures are considerably more difficult to acquire. Clutter et al. (1983) recognized this problem when stating ' $\ldots$ the number of people who think they can accurately estimate upper-stem diameters is disturbingly larger than the number of people who can, in fact, actually produce estimates of reasonable accuracy.' The difficulty in measurement primarily arises from the distance between the observer and the point to be measured (Weaver et al. 2015); however, other factors such as visual obstruction and measurement method (e.g., ocular vs. instrument) can also play a role. 
Despite the difficulties associated with upper-stem measurements, they are still commonly used in many surveys and are even suggested as additional data by which taper models can be locally calibrated (Trincado and Burkhart 2006; Sabatia and Burkhart 2015; Cao and Wang 2015). In some cases, models are used to estimate upperstem diameters for situations where the data are not available (Clark et al. 1991). Whether these data are observed or predicted, they are often used in a manner that assumes they are without error. However, studies have shown that uncertainty in the form of both variability and systematic deviations ${ }^{1}$ may be present (Williams et al. 1999; Kalliovirta et al. 2004). Due to the importance of upper-stem diameter determination, it is important to understand the effects of uncertainty in both observed and predicted upper-stem diameter data on individual-tree volume predictions and subsequent population estimates of total volume.

In this study, the analytical focus was on the diameter at $5.27 \mathrm{~m}$ height along the bole, as this point is of particular interest for describing tree form (Clark et al. 1991; Czaplewski and McClure 1988). When evaluating the taper model presented by Clark et al. (1991), Li and Weiskittel (2010) found that interpolation of the diameter at $5.27 \mathrm{~m}$ between two measurement points in tree taper data resulted in less systematic deviation and uncertainty in taper model predictions than using predicted values from a model. However, in most practical applications, accurate upperstem measures such as those found in tree taper data are not available. Therefore, the objectives of this study are threefold: (1) to empirically describe the uncertainty in diameter at $5.27 \mathrm{~m}$ for both standing tree measurements and model predictions, (2) to assess the effects of these sources of uncertainty on individual-tree volume predictions via a taper model, and (3) to evaluate the resultant consequences on large-area estimates of total volume.

\section{Methods}

\section{Data}

Several data sources were used in the analyses. Measurement uncertainty of upper-stem diameter was assessed using two datasets: (1) data collected using Criterion ${ }^{\mathrm{TM}}$ laser and Haglöf ${ }^{\circledR}$ Gator Eyes equipment as part of an ongoing field study, and (2) quality assurance (QA) and associated inventory production (IP) data from the Forest

\footnotetext{
${ }^{1}$ Measurement errors (deviations from true values) do not necessarily contribute to bias in estimators of population parameters unless the mean of the distribution of the errors deviates from 0 (systematic measurement error) or if the distribution is non-symmetric.
}

Inventory and Analysis (FIA) program of the U.S. Forest Service (Pollard et al. 2006). Quantifying uncertainty due to a prediction model for upper-stem diameters was accomplished via data from a regional tree taper study (Westfall and Scott 2010). These data were used to fit the upper-stem diameter prediction model of Clark et al. (1991), which provided the necessary statistics for both residual error and uncertainty of the estimated model parameters. Finally, the effects of measurement and model prediction uncertainty were assessed using FIA data collected from 2009 to 2013 across the state of Maine, USA. Each dataset is described in more detail in subsequent sections.

\section{Observed upper-stem diameter uncertainty}

Measurements of upper-stem diameters can be obtained using various field protocols; however, electronic measurement devices are commonly used in current fieldwork methods. In this study, upper-stem measurements taken using Criterion ${ }^{\mathrm{TM}}$ RD1000 laser dendrometer and Haglöf ${ }^{\circledR}$ Gator Eyes calipers were evaluated. The Criterion and Gator Eyes data were obtained from fieldwork in Maine and Virginia during an ongoing study involving measurements from standing and felled trees (Westfall et al. 2012). Criterion measurements were collected on 124 trees, of which 50 were softwood species [primarily balsam fir (Abies balsamea L.) and white pine (Pinus strobus L.)] and 74 were hardwood species [primarily red maple (Acer rubrum L.) and white oak (Quercus alba L.)]. Gator Eyes measurements were recorded on 104 trees having similar attributes as those described for the Criterion sample. Diameters were recorded at multiple heights along the stem on standing trees, with 1-3 measurement points recorded on each tree between 4.36 and $6.19 \mathrm{~m}$ height (within $1 \mathrm{~m}$ of $5.27 \mathrm{~m}$; Table 1). The described height range was used to approximate the accuracy and precision of diameter measurements at $5.27 \mathrm{~m}$. This was accomplished by comparing the measured diameters to the assumed 'true' diameters obtained from caliper measurements taken at the same point after the tree was felled.

$\hat{D}_{i j}=\hat{d}_{(F) i j}-\hat{d}_{(S) i j}$

where $\hat{d}_{(F) i j}$ is the felled-tree upper-stem diameter for tree $i$, plot $j, \hat{d}_{(S) i j}$ is the corresponding upper-stem diameter measured on the standing tree, and $\hat{D}_{i j}$ is the upper-stem diameter difference between the felled and standing tree measurements. To maximize sample sizes, species were aggregated into hardwood/softwood species groups for analysis (Table 1).

A broader assessment of uncertainty in measurement of diameter at $5.27 \mathrm{~m}$ tree height was also conducted using 
Table 1 Number of observations and mean difference $(\bar{D})$ and standard deviation $\left(\mathrm{SD}_{\bar{D}}\right)$ in upper-stem diameter $(\mathrm{cm})$ measurements between 4.36 and $6.19 \mathrm{~m}$ height for hardwood and softwood species groups; estimated parameters for model (6) (Criterion/Gator Eyes) and model (7) (inventory)

\begin{tabular}{|c|c|c|c|c|c|c|c|c|}
\hline \multirow[t]{2}{*}{ Measurement } & \multicolumn{3}{|c|}{ Hardwood } & \multicolumn{3}{|c|}{ Softwood } & \multicolumn{2}{|c|}{ All species } \\
\hline & \# obs. & $\bar{D}(\mathrm{~cm})$ & $\mathrm{SD}_{\bar{D}}$ & \# obs. & $\bar{D}(\mathrm{~cm})$ & $\mathrm{SD}_{\bar{D}}$ & $\phi_{0}$ & $\phi_{1}$ \\
\hline Inventory & 780 & $-0.365^{\mathrm{a}}$ & 3.63 & 330 & $-0.679^{\mathrm{a}}$ & 4.34 & 0.2878 & 1.0250 \\
\hline Criterion & 153 & 0.175 & 1.60 & 127 & 0.002 & 1.66 & 0.1140 & 0.7908 \\
\hline Gator eyes & 129 & 0.068 & 1.48 & 98 & 0.759 & 1.21 & 0.2547 & 0.5158 \\
\hline
\end{tabular}

a At height of approximately $12 \mathrm{~m}$

combined inventory production (IP) and quality assurance (QA) data. These data were collected by FIA during the 2007 and 2008 field seasons across 13 states in the northeastern USA. These data did not include explicit upperstem diameter measurements; however, in addition to measurements of $\mathrm{dbh}$ and total tree height, there were merchantable height measurements to specified top-diameter limits for sawtimber volume calculations $(22.9 \mathrm{~cm}$ for hardwood trees $27.9 \mathrm{~cm}$ dbh and larger; $17.8 \mathrm{~cm}$ for softwood trees $22.9 \mathrm{~cm}$ dbh and larger; U.S. Forest Service 2006). The height measurements were obtained using various measurement methods (ocular, clinometer, laser, etc.) as part of normal operational inventory procedures. Data from the same sample trees in both the IP and QA data were paired for assessment of differences between crews. Because specific diameter measurement points were targeted, the differences in the height measurements were assumed to arise from differences in upper-stem diameter assessment. To convert this information into differences in upper-stem diameters, the observed dbh, total height $(H)$, and merchantable height $(h)$ data were used in conjunction with taper models from Westfall and Scott (2010) to predict the upper-stem diameters at the merchantable height (h). Between-crew diameter differences for each measurement point provided information on how much field measurements of upper-stem diameters vary from crew-tocrew when using standard field techniques and tools.

$\hat{D}_{i j}=\hat{d}_{(\mathrm{QA}) i j}-\hat{d}_{(\mathrm{IP}) i j}$

where $\hat{d}_{(\mathrm{QA}) i j}$ is the predicted QA crew upper-stem diameter for tree $i$, plot $j, \hat{d}_{(\mathrm{IP}) i j}$ is the corresponding upper-stem diameter for the IP crew, and $\hat{D}_{i j}$ is the predicted upperstem diameter difference between the QA and IP crew. The values obtained using (2) are modeled approximations of the actual (unknown) measurement differences. Note that $\hat{D}_{i j}$ is used in both (1) and (2) to generally refer to differences in upper-stem diameter measurements when measured by two methods or by two crews independently.

To obtain estimates of variability, data associated with each measurement type/species group combination (Table 1) were then sorted by measurement height values and assigned to $G$ groups of $n_{g} \approx 20$ observations each $(g=1, \ldots, G)$. For each of these groups, the average measurement height, average dbh, and standard deviation of the upper-stem diameter differences were calculated.

$\bar{h}_{g}=\frac{\sum h_{(g) i j}}{n_{g}}$

$\overline{\mathrm{dbh}}_{g}=\frac{\sum \mathrm{dbh}_{(g) i j}}{n_{g}}$

$\hat{\sigma}_{\hat{D}_{g}}=\sqrt{\frac{\sum\left(\hat{D}_{(g) i j}-\hat{\bar{D}}_{(g) i j}\right)^{2}}{n_{g}-1}}$.

These group values were used to fit a nonlinear regression model to describe the variability of upper-stem diameters as a function of dbh and merchantable height (McRoberts and Westfall 2014). To obtain sufficient sample sizes for each measurement type, the analyses were conducted using all available data. For the Criterion and Gator Eyes measurements between 4.36 and $6.19 \mathrm{~m}$ height, a statistically significant $(\alpha=0.05)$ relationship between $\hat{\sigma}_{\hat{D}_{g}}$ and $\overline{\mathrm{dbh}}_{g}$ was formulated as

$\hat{\sigma}_{\hat{D}_{g}}=\phi_{0}{\overline{\mathrm{dbh}_{g}}}_{\phi_{1}}+\varepsilon_{g}$.

Similarly, both $\overline{\operatorname{dbh}}_{g}$ and $\bar{h}_{g}$ were used to construct a statistically significant relationship between tree size attributes and measurement variability for the inventory data using the model form:

$\hat{\sigma}_{\hat{D}_{g}}=\overline{\mathrm{dbh}}_{g}^{\phi_{0}} \phi_{1}^{\bar{h}_{g}}+\varepsilon_{g}$

where $\phi$ s are parameters to be estimated (Table 1) and $\varepsilon_{g}$ is a random error term. Predictions of the standard deviation for diameter measurement differences at $5.27 \mathrm{~m}\left(\hat{\sigma}_{\hat{D}}^{*}\right)$ for individual trees were obtained by substituting $\overline{\mathrm{dbh}}_{g}=\mathrm{dbh}_{i j}$ and $\bar{h}_{g}=5.27$ as appropriate.

\section{Predicted upper-stem diameter uncertainty}

An alternative to measuring upper-stem diameters at $5.27 \mathrm{~m}$ during field operations is to predict the desired 
values from a statistical model. To properly assess the effects of substituting model predictions for measured diameters into the volume model, uncertainty in the model parameter estimates as well as the residual error needs to be accommodated (McRoberts and Westfall 2014). To obtain reliable estimates for these sources of variability, models were fitted directly to observed data. The model fitting data were from Westfall and Scott (2010) where the bole diameter at $5.27 \mathrm{~m}\left(\hat{d}_{i j}^{*}\right)$ was linearly interpolated from the nearest measures above and below $5.27 \mathrm{~m}$, similar to $\mathrm{Li}$ and Weiskittel (2010). Due to the popularity of the Clark et al. (1991) taper models, their model specification for upper-stem diameter at $5.27 \mathrm{~m}$ was used.

$\hat{d}_{i j}^{*}=\operatorname{dbh}_{i j}\left(\beta_{0}+\beta_{1}\left(5.27 / H_{i j}\right)^{2}\right)+\varepsilon_{i j}$

where $\hat{d}_{i j}^{*}$ is the predicted outside-bark diameter $(\mathrm{cm})$ at $5.27 \mathrm{~m}, \beta \mathrm{s}$ are parameters to be estimated, and $\varepsilon_{i j}$ are residual random errors.

Due to the heteroskedastic nature of the $\varepsilon_{i j}$ in (8), the residual variance was modeled as a function of $\hat{d}_{i j}^{*}$. To do so, the data were ordered by $\hat{d}_{i j}^{*}$ and grouped into $Q$ groups of approximately $n_{q}=10$ observations each $(q=1, \ldots, Q$; $Q=12)$. For each of these groups, the average predicted upper-stem diameter $\hat{\bar{d}}_{q}^{*}$ and standard deviation of residuals $\hat{\sigma}_{q}$ were calculated.

$\hat{\bar{d}}_{q}^{*}=\frac{\sum \hat{d}_{(q) i j}^{*}}{n_{q}}$

$\hat{\sigma}_{q}=\sqrt{\frac{\sum\left(\varepsilon_{(q) i j}-\bar{\varepsilon}_{q}\right)^{2}}{n_{q}-1}}$

where in group $q, \varepsilon_{(q) i j}$ is the residual error for tree $i$ on plot $j$ and $\bar{\varepsilon}_{q}$ is the mean residual error. Subsequently, these $Q$ data points were used to fit the following model to estimate the residual variance,

$\hat{\sigma}_{q}=\gamma_{0} \hat{\bar{d}}_{q}^{* \gamma_{1}}+\varepsilon$

where $\gamma \mathrm{s}$ are parameters to be estimated and $\varepsilon$ are the residual random errors.

Due to the trade-off between $n_{q}$ and $Q$, and the need for a sufficient number $(Q)$ of data points to fit model (11), a resampling approach was taken to ensure robust estimates of the parameters. Specifically, within each group $q$, observations were randomly selected with replacement to achieve a sample size of $n_{q}$ and the calculations and model fitting associated with (9), (10), (11) were performed. This process was repeated 10,000 times, and the mean values of the parameter estimates in (11) were calculated.

Uncertainty in regard to the estimated parameters in model (8) was accommodated via a resampling approach having three steps: (1) observations were randomly selected with replacement from the original data until the original sample size was achieved, (2) model (8) was fitted to these data and estimates of parameters calculated and stored, and (3) steps 1 and 2 were repeated 10,000 times to obtain a joint distribution of the model parameter estimates that implicitly accounts for the covariance between the estimates and describes the range of variability in the estimates.

\section{Assessment of total uncertainty}

The data used to conduct the analysis of overall uncertainty were collected by the FIA program from 2009 to 2013 in Maine, USA. The analyses focused on balsam fir and red maple tree species, with minimum tree size requirements of $\mathrm{dbh} \geq 12.7 \mathrm{~cm}$ and $H \geq 8.2 \mathrm{~m}$ (Table 2). The methods described above that quantify the uncertainty due to measurements/model predictions are subject to various assumptions and procedural subjectivity, e.g., regression analyses. Thus, the methods provide approximate values for upper-stem measurement systematic deviations and variability. However, the outcomes can be used to ascertain a practical range of values that might be encountered under various measurement or modeling approaches. Uncertainty in the Clark et al. (1991) taper model predictions of individual-tree volume was not assessed as (1) it would affect all analyses similarly, (2) quantifying this source of uncertainty was not an objective of this study, and (3) it is common for tree volume prediction error to be ignored in forest inventory uncertainty estimates.

The amount of systematic deviation from 'true' values, if any, in observed diameter measurements at $5.27 \mathrm{~m}$ is unclear. Table 1 indicates large variability in these assessments for Criterion and Gator Eyes devices; the statistical significance of $\bar{D} \neq 0$ was not considered particularly relevant given the sample size effect on the outcome and that the practical differences could be negligible. An assessment of systematic measurement deviation from the large-scale inventory data was not possible at $5.27 \mathrm{~m}$, but mean differences of 0.36 (hardwoods) and $0.68 \mathrm{~cm}$ (softwoods) were found at a mean measurement height of approximately $12 \mathrm{~m}$. Presumably, these differences would

Table 2 Summary statistics for balsam fir and red maple trees from FIA data in Maine 2009-2013

\begin{tabular}{|c|c|c|c|c|c|c|c|}
\hline \multirow[t]{2}{*}{ Species } & \multirow[t]{2}{*}{$\#$ trees } & \multicolumn{3}{|c|}{ Dbh $(\mathrm{cm})$} & \multicolumn{3}{|c|}{ Total height (m) } \\
\hline & & Min. & Mean & Max. & Min. & Mean & Max. \\
\hline Balsam fir & 18,477 & 12.7 & 17.0 & 45.2 & 8.2 & 12.2 & 25.3 \\
\hline Red maple & 13,947 & 12.7 & 20.1 & 74.2 & 8.2 & 15.7 & 29.3 \\
\hline
\end{tabular}


be smaller at $5.27 \mathrm{~m}$ due to the closer proximity of the measurement to the observer, but this hypothesis remains untested. As such, the sensitivity of estimates to systematic measurement deviation $(S)$ was evaluated for values ranging from -1 to $1 \mathrm{~cm}$ in increments of $0.5 \mathrm{~cm}$. Because there were no measurements at $5.27 \mathrm{~m}$ in these FIA data from Maine, the upper-stem diameter at this point $\left(\hat{d}_{i j}^{*}\right)$ was predicted from model (8). In the analyses, these values were treated as observations without error as a substitute for unknown 'true' values about which measurements may vary. Systematic measurement deviations and uncertainty were introduced by applying variation to $\hat{d}_{i j}^{*}$ by (1) selecting a random variate $z$ from a standard $N(0,1)$ distribution, (2) multiplying $z$ by the measurement standard deviation $\left(\hat{\sigma}_{\hat{D}}^{*}\right)$ obtained from model (6) or (7) as applicable, (3) adding the result to the original $\hat{d}_{i j}^{*}$ value, and (4) adding $S$ (if any):

$\hat{d}_{i j}^{\sim}=\hat{d}_{i j}^{*}+z \hat{\sigma}_{\hat{D}}^{*}+S$

The value of $\hat{d}_{i j}^{\sim}$ was subject to constraints of $\hat{d}_{i j}^{\sim}<\mathrm{dbh}$ and $\bar{z} \approx 0$; to maintain $\bar{z} \approx 0, \hat{\sigma}_{\hat{D}}^{*}$ was iteratively reduced via multiplication by 0.9 until $\hat{d}_{i j}^{\sim}<\mathrm{dbh}$ was attained. Potential correlations of errors between trees occurring on the same sample plot were not considered due to the negligible contribution to the total variance (Breidenbach et al. 2014).

An assessment of the uncertainty when an upper-stem diameter prediction model is used requires a different approach. Specifically, $\hat{d}_{i j}^{\prime}$ arises from a random selection of paired parameter estimates obtained from the resampling exercise conducted with model (8). Additionally, accounting for residual variance is accomplished using model (11) with $\hat{d}_{i j}^{\prime}$ as the predictor variable. As done previously, the predicted standard deviation is multiplied by a $N(0,1)$ random variate to obtain values for individual trees. The resultant perturbed upper-stem diameter due to model variability is:

$\hat{d}_{i j}^{\sim}=\hat{d}_{i j}^{\prime}+z \hat{\sigma}_{\varepsilon}$

Based on assessments of residuals, the model predictions were assumed to be unbiased.

The effect of using $\hat{d}_{i j}^{\sim}$ instead of $\hat{d}_{i j}^{*}$ was assessed by comparing resultant individual-tree volume predictions $\left(\mathrm{m}^{3}\right)$ from $0.3 \mathrm{~m}$ stump height to $10.2 \mathrm{~cm}$ top-diameter limit. These predicted volumes were obtained by first fitting the total-height taper model of Clark et al. (1991, Model 2) to the respective balsam fir and red maple species data described in Westfall and Scott (2010). Integration of this model provided the basis for the tree volume predictions (Clark et al. 1991, Model 3). The differences in predicted tree volumes were assessed via:

$R\left(\hat{V}_{i j}\right)=\hat{V}_{i j}^{\sim} / \hat{V}_{i j}^{*}$

where $\hat{V}_{i j}^{*}$ is the predicted tree volume $\left(\mathrm{m}^{3}\right)$ based on $\hat{d}_{i j}^{*}$, $\hat{V}_{i j}^{\sim}$ is the predicted tree volume $\left(\mathrm{m}^{3}\right)$ based on $\hat{d}_{i j}^{\sim}$, and $R\left(\hat{V}_{i j}\right)$ is the ratio of the volumes.

The implications of using $\hat{d}_{i j}^{\sim}$ versus $\hat{d}_{i j}^{*}$ for estimates of population totals were assessed by summing the associated tree volumes to the plot level, expanding to a per-unit area basis, and using the post-stratified estimation methods described in Scott et al. (2005). Consistent with FIA methods in the study area, five strata were constructed based on percent canopy cover classes of 0 5, 6-50, 51-65, 66-80, 81-100\% (Westfall et al. 2011). The plots were assigned to strata using plot center locations and the National Land Cover Database (NLCD) canopy cover map (Homer et al. 2004). The estimators for the population total and its variance are (Scott et al. 2005):

$\hat{T}=A \sum W_{h} \frac{\sum \hat{V}_{j h}}{m_{h}}$

$\operatorname{Var}(\hat{T})=\frac{A^{2}}{m}\left[\sum W_{h} m_{h} \operatorname{Var}\left(\bar{V}_{h}\right)+\sum\left(1-W_{h}\right) \frac{m_{h}}{m} \operatorname{Var}\left(\bar{V}_{h}\right)\right]$

where $\hat{T}$ is the estimated population total $\left(\mathrm{m}^{3}\right), A$ is the population area (ha), $W_{h}$ is the weight for stratum $h, \hat{V}_{j h}$ is the volume $\left(\mathrm{m}^{3} / \mathrm{ha}\right)$ of plot $j$ in stratum $h, m_{h}$ is the number of plots in stratum $h, \bar{V}_{h}$ is the mean plot volume $\left(\mathrm{m}^{3} / \mathrm{ha}\right)$ in stratum $h$, and $m$ is the total number of plots. Baseline values for $\hat{T}$ and $\operatorname{Var}(\hat{T})$ were calculated using the observed data with no variability or systematic deviation included. Corresponding estimates based on the use of $\hat{d}_{i j}^{\sim}$ instead of $\hat{d}_{i j}^{*}$ were calculated to evaluate nonzero additional variance and systematic deviations.

The effects of upper-stem diameter uncertainty on individual-tree volume predictions and estimates of population totals were assessed using a Monte Carlo simulation (Shettles et al. 2015; McRoberts et al. 2015). For each of 5000 replications, the procedures outlined above were applied and results summarized in terms of distributions of $R\left(\hat{V}_{i j}^{r}\right)$ for individual trees and $\hat{T}^{r}$ and $\operatorname{Var}\left(\hat{T}^{r}\right)$ for population estimates, where $r(=1, \ldots, 5000)$ indicates the replication. The additional variance due to measurement/model variability was estimated from

$\hat{T}^{\Delta}=\frac{1}{n_{r}} \sum_{r=1}^{n_{r}} \hat{T}^{r}$ 
$\operatorname{Var}\left(\hat{T}^{\Delta}\right)=\frac{1}{n_{r}-1} \sum_{r=1}^{n_{r}}\left(\hat{T}^{r}-\hat{T}^{\Delta}\right)^{2}$

and the overall uncertainty was assessed via

$\operatorname{MSE}^{\Delta}=\operatorname{Var}(\hat{T})+\operatorname{Var}\left(\hat{T}^{\Delta}\right)+\left(S^{\Delta}\right)^{2}$

where $\mathrm{MSE}^{\Delta}$ is the mean squared error and $S^{\Delta}=\hat{T}-\hat{T}^{\Delta}$. The standard error of the estimate is defined as $\mathrm{SE}^{\Delta}=\sqrt{\mathrm{MSE}^{\Delta}}$. The percent change in standard error attributable to upper-stem diameter uncertainty was calculated as:

$\% D_{(\mathrm{SE})}=100\left(1-\frac{\sqrt{\operatorname{Var}(\hat{T})}}{\mathrm{SE}^{\Delta}}\right)$.

For comparative purposes, individual-tree volume predictions and population estimates were also calculated using a taper model that does not use upper-stem measurements. The predicted tree volumes, denoted $\hat{V}_{i j}^{0}$, for each species were obtained using the taper models presented by Westfall and Scott (2010). The $\hat{V}_{i j}^{0}$ were compared to $\hat{V}_{i j}^{*}$ for assessment of differences in predicted tree volumes between the two taper models using:

$R\left(\hat{V}_{i j}^{0}\right)=\hat{V}_{i j}^{0} / \hat{V}_{i j}^{*}$

Also, the $\hat{V}_{i j}^{0}$ were used to produce population estimates $\left(\hat{T}^{0}\right)$ and associated variances $\left(\operatorname{Var}\left(\hat{T}^{0}\right)\right)$. Calculation of standard errors and percent differences between these estimates and those obtained from the Clark et al. (1991) model proceeded as described above with $\hat{T}^{0}$ replacing $\hat{T}$. These comparative analyses were not undertaken to determine which taper model performed better, rather to assess the potential effects on tree volume and population estimates when not using upper-stem diameter information.

\section{Results}

\section{Objective 1}

Prediction of diameter measurement variability at $5.27 \mathrm{~m}$ via models (6) and (7) showed several patterns in relation to the measurement type. First, it was clear that the electronic measurement devices exhibited less measurement variability than general inventory methods (Fig. 1). Second, measurement variation increased as tree size (dbh) increased regardless of measurement type (McRoberts et al. 1994). Lastly, while the magnitudes were considerably different, the degree of nonlinearity between variability and tree size for the general inventory and Gator Eyes measurements were quite similar, whereas the

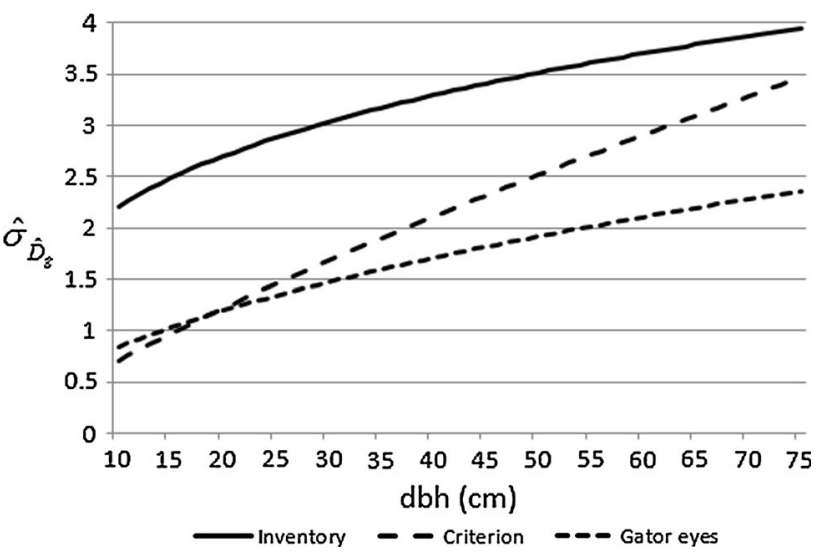

Fig. 1 Relationship between tree $\mathrm{dbh}(\mathrm{cm})$ and standard deviation $(\mathrm{cm})$ of diameter measurement at $5.27 \mathrm{~m}$ for three different measurement types

relationship was nearly linear for Criterion measurements. Limited differences between the hardwood and softwood groups were observed.

\section{Objective 2}

The additional imprecision in population estimates of cubic volume due to measurement uncertainty reflected the trends exhibited in Fig. 1. The increase in standard error for the population total $\left(\hat{T}^{\Delta}\right)$ when no systematic deviation was present ranged from 0.4 to 2.2 percent for red maple and from 0.4 to $3.9 \%$ for balsam fir (Table 3). The smallest impact of measurement variability was associated with the electronic measurement devices (Criterion/Gator Eyes), with the general inventory methods having substantially larger contributions to overall uncertainty. The other relevant factor to measurement uncertainty pertains to potential systematic deviations in the measurements. The percent increase in standard error rises dramatically when systematic deviations are present, to the extent that a $1.0-\mathrm{cm}$ deviation in either direction increases standard errors by $40-55 \%$ when compared to no deviation in measurements (Table 3 ). In addition, systematic deviations also considerably affect the estimate of the population total. In this analysis, a systematic measurement deviation of $1.0 \mathrm{~cm}$ resulted in approximately a $5.5 \%$ increase in the estimate of the population total. Similarly, a systematic measurement deviation of $-1.0 \mathrm{~cm}$ produced estimates of population totals that were on average about $5.1 \%$ smaller than when no systematic deviation was present.

\section{Objective 3}

In regard to using model (8) to predict upper-stem diameters, the two components of additional uncertainty were in the estimates of the model parameters and the residual 
Table 3 Systematic measurement deviation $(S)$, population estimates $\left(\hat{T}^{\Delta}\right)$, systematic estimate deviation $\left(S^{\Delta}\right)$, additional variance due to measurement uncertainty $\left(\operatorname{Var}\left(\hat{T}^{\Delta}\right)\right)$, total mean squared error of the estimate $\left(\mathrm{MSE}^{\Delta}\right)$ and associated sampling error $\left(\mathrm{SE}^{\Delta}\right)$, and

\begin{tabular}{|c|c|c|c|c|c|c|c|c|}
\hline Species & Measurement type & $S(\mathrm{~cm})$ & $\hat{T}^{\Delta}$ & $S^{\Delta}$ & $\operatorname{Var}\left(\hat{T}^{\Delta}\right)$ & $\operatorname{MSE}^{\Delta}$ & $\mathrm{SE}^{\Delta}$ & $\% D_{(\mathrm{SE})}$ \\
\hline \multirow[t]{15}{*}{ Red maple } & Inventory & -1 & $2.58 \mathrm{E}+08$ & $-1.22 \mathrm{E}+07$ & $2.17 \mathrm{E}+11$ & $2.23 \mathrm{E}+14$ & $14,919,786$ & 42.3 \\
\hline & Inventory & -0.5 & $2.65 \mathrm{E}+08$ & $-5.24 \mathrm{E}+06$ & $2.26 \mathrm{E}+11$ & $1.04 \mathrm{E}+14$ & $10,184,105$ & 15.5 \\
\hline & Inventory & 0 & $2.72 \mathrm{E}+08$ & $1.77 \mathrm{E}+06$ & $2.15 \mathrm{E}+11$ & $7.75 \mathrm{E}+13$ & $8,802,556$ & 2.2 \\
\hline & Inventory & 0.5 & $2.79 \mathrm{E}+08$ & $8.83 \mathrm{E}+06$ & $2.24 \mathrm{E}+11$ & $1.54 \mathrm{E}+14$ & $12,417,528$ & 30.7 \\
\hline & Inventory & 1 & $2.86 \mathrm{E}+08$ & $1.58 \mathrm{E}+07$ & $2.19 \mathrm{E}+11$ & $3.25 \mathrm{E}+14$ & $18,018,601$ & 52.2 \\
\hline & Criterion & -1 & $2.56 \mathrm{E}+08$ & $-1.40 \mathrm{E}+07$ & $7.55 \mathrm{E}+10$ & $2.70 \mathrm{E}+14$ & $16,435,936$ & 47.6 \\
\hline & Criterion & -0.5 & $2.64 \mathrm{E}+08$ & $-6.70 \mathrm{E}+06$ & $7.97 \mathrm{E}+10$ & $1.21 \mathrm{E}+14$ & $11,015,444$ & 21.8 \\
\hline & Criterion & 0 & $2.71 \mathrm{E}+08$ & $7.82 \mathrm{E}+05$ & $7.91 \mathrm{E}+10$ & $7.48 \mathrm{E}+13$ & $8,649,624$ & 0.5 \\
\hline & Criterion & 0.5 & $2.79 \mathrm{E}+08$ & $8.47 \mathrm{E}+06$ & $8.33 \mathrm{E}+10$ & $1.48 \mathrm{E}+14$ & $12,184,006$ & 29.3 \\
\hline & Criterion & 1 & $2.87 \mathrm{E}+08$ & $1.63 \mathrm{E}+07$ & $8.67 \mathrm{E}+10$ & $3.41 \mathrm{E}+14$ & $18,462,665$ & 53.4 \\
\hline & Gator eyes & -1 & $2.56 \mathrm{E}+08$ & $-1.41 \mathrm{E}+07$ & $5.59 \mathrm{E}+10$ & $2.73 E+14$ & $16,520,896$ & 47.9 \\
\hline & Gator eyes & -0.5 & $2.64 \mathrm{E}+08$ & $-6.81 \mathrm{E}+06$ & $5.72 \mathrm{E}+10$ & $1.23 \mathrm{E}+14$ & $11,079,937$ & 22.3 \\
\hline & Gator eyes & 0 & $2.71 \mathrm{E}+08$ & $6.85 \mathrm{E}+05$ & $6.08 \mathrm{E}+10$ & $7.47 \mathrm{E}+13$ & $8,640,312$ & 0.4 \\
\hline & Gator eyes & 0.5 & $2.79 \mathrm{E}+08$ & $8.39 \mathrm{E}+06$ & $6.16 \mathrm{E}+10$ & $1.47 \mathrm{E}+14$ & $12,123,737$ & 29.0 \\
\hline & Gator eyes & 1 & $2.87 \mathrm{E}+08$ & $1.63 \mathrm{E}+07$ & $6.37 \mathrm{E}+10$ & $3.39 \mathrm{E}+14$ & $18,411,410$ & 53.2 \\
\hline \multirow[t]{15}{*}{ Balsam fir } & Inventory & -1 & $1.89 \mathrm{E}+08$ & $-8.24 \mathrm{E}+06$ & $7.64 \mathrm{E}+10$ & $1.04 \mathrm{E}+14$ & $10,191,663$ & 41.2 \\
\hline & Inventory & -0.5 & $1.94 \mathrm{E}+08$ & $-3.31 \mathrm{E}+06$ & $8.00 \mathrm{E}+10$ & $4.79 \mathrm{E}+13$ & $6,918,526$ & 13.4 \\
\hline & Inventory & 0 & $1.99 \mathrm{E}+08$ & $1.70 \mathrm{E}+06$ & $7.82 \mathrm{E}+10$ & $3.88 \mathrm{E}+13$ & $6,232,736$ & 3.9 \\
\hline & Inventory & 0.5 & $2.04 \mathrm{E}+08$ & $6.76 \mathrm{E}+06$ & $8.15 \mathrm{E}+10$ & $8.27 \mathrm{E}+13$ & $9,091,397$ & 34.1 \\
\hline & Inventory & 1 & $2.09 \mathrm{E}+08$ & $1.18 \mathrm{E}+07$ & $7.96 \mathrm{E}+10$ & $1.76 \mathrm{E}+14$ & $13,247,641$ & 54.8 \\
\hline & Criterion & -1 & $1.87 \mathrm{E}+08$ & $-9.97 \mathrm{E}+06$ & $2.02 \mathrm{E}+10$ & $1.35 \mathrm{E}+14$ & $11,627,553$ & 48.5 \\
\hline & Criterion & -0.5 & $1.92 \mathrm{E}+08$ & $-4.81 \mathrm{E}+06$ & $2.20 \mathrm{E}+10$ & $6.01 \mathrm{E}+13$ & $7,753,773$ & 22.8 \\
\hline & Criterion & 0 & $1.98 \mathrm{E}+08$ & $5.37 \mathrm{E}+05$ & $2.31 \mathrm{E}+10$ & $3.62 \mathrm{E}+13$ & $6,015,314$ & 0.4 \\
\hline & Criterion & 0.5 & $2.03 E+08$ & $6.06 \mathrm{E}+06$ & $2.44 \mathrm{E}+10$ & $7.39 \mathrm{E}+13$ & $8,597,558$ & 30.3 \\
\hline & Criterion & 1 & $2.09 \mathrm{E}+08$ & $1.18 \mathrm{E}+07$ & $2.51 \mathrm{E}+10$ & $1.74 \mathrm{E}+14$ & $13,199,621$ & 54.6 \\
\hline & Gator eyes & -1 & $1.87 \mathrm{E}+08$ & $-9.98 \mathrm{E}+06$ & $1.75 \mathrm{E}+10$ & $1.36 \mathrm{E}+14$ & $11,643,883$ & 48.6 \\
\hline & Gator eyes & -0.5 & $1.92 \mathrm{E}+08$ & $-4.83 \mathrm{E}+06$ & $1.81 \mathrm{E}+10$ & $6.03 \mathrm{E}+13$ & $7,765,533$ & 22.9 \\
\hline & Gator eyes & 0 & $1.98 \mathrm{E}+08$ & $5.15 \mathrm{E}+05$ & $1.94 \mathrm{E}+10$ & $3.62 \mathrm{E}+13$ & $6,013,069$ & 0.4 \\
\hline & Gator eyes & 0.5 & $2.03 \mathrm{E}+08$ & $6.05 \mathrm{E}+06$ & $2.04 \mathrm{E}+10$ & $7.37 \mathrm{E}+13$ & $8,584,637$ & 30.2 \\
\hline & Gator eyes & 1 & $2.09 \mathrm{E}+08$ & $1.17 \mathrm{E}+07$ & $2.13 \mathrm{E}+10$ & $1.74 \mathrm{E}+14$ & $13,185,598$ & 54.6 \\
\hline
\end{tabular}

variance. The resultant distribution and covariance of the parameter estimates from the resampling exercise are illustrated using the red maple data (Fig. 2). The predicted residual variance from (11) using the parameter estimates given in Table 4 shows the residual variance increases approximately linearly as tree size (dbh) increases (Fig. 3). Applying these two sources of uncertainty to individual trees and generating estimates of population total cubic volume indicated an average of 5.8 and $11.0 \%$ increase in standard errors for red maple and balsam fir, respectively (Table 4).

In the context of individual trees, incorporation of model uncertainty sometimes resulted in considerably different volumes than were predicted using the original data. For percent difference in sampling error $\left(\% D_{(\mathrm{SE})}\right)$ in comparison with $\sqrt{\operatorname{Var}(\hat{T})}$ 
Table 4 Estimated parameters for model (10), population estimates $(\hat{T})$ and associated variances $\operatorname{Var}(\hat{T})$, additional variance due to model uncertainty $\left(\operatorname{Var}\left(\hat{T}^{\Delta}\right)\right)$, sampling error $\left(\mathrm{SE}^{\Delta}\right)$, and percent difference in sampling error $\left(\% D_{(\mathrm{SE})}\right)$ in comparison with $\sqrt{\operatorname{Var}(\hat{T})}$

\begin{tabular}{lllllrr}
\hline Species & $\gamma_{0}$ & $\gamma_{1}$ & $\hat{T}\left(\mathrm{~m}^{3}\right)$ & $\operatorname{Var}(\hat{T})$ & $\operatorname{Var}\left(\hat{T}^{\Delta}\right)$ & $\mathrm{SE}^{\Delta}$ \\
\hline Red maple & 0.14864 & 0.82390 & $2.7073 \mathrm{E}+08$ & $7.4488 \mathrm{E}+13$ & $9.4184 \mathrm{E}+12$ & 9160044 \\
Balsam fir & 0.14291 & 0.75749 & $1.9506 \mathrm{E}+08$ & $3.5029 \mathrm{E}+13$ & $9.1626 \mathrm{E}+12$ & 6647676 \\
\hline
\end{tabular}

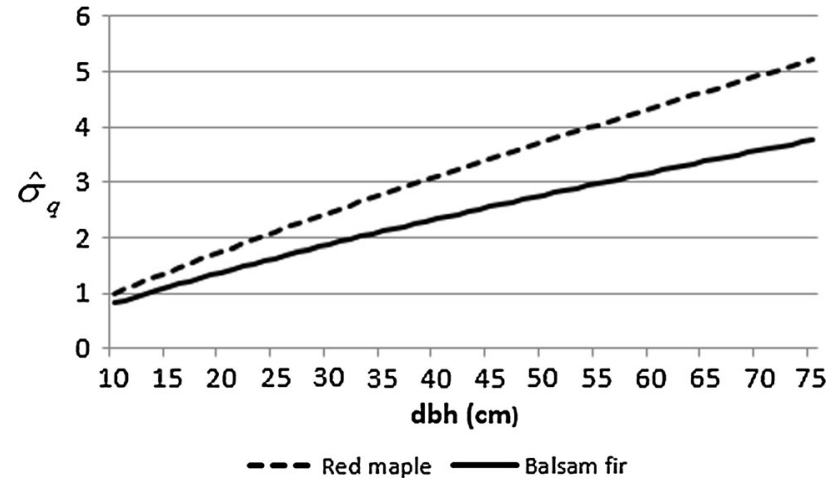

Fig. 3 Predicted standard deviation $(\mathrm{cm})$ of residual error from model (11) in relation to tree $\mathrm{dbh}(\mathrm{cm})$ for red maple and balsam fir

red maple, the most extreme volume reduction was $57 \%$ of the original value, while the largest volume increase was $176 \%$ of the original value (Fig. 4). The range of differences for balsam fir was somewhat less with the least volume being $61 \%$ and the largest difference being $151 \%$ of the original volume. Over the 5000 iterations, the tree volumes were on average consistent with the original value (as expected).

The comparisons between the Clark et al. (1991) model and an alternative taper model (WS; Westfall and Scott

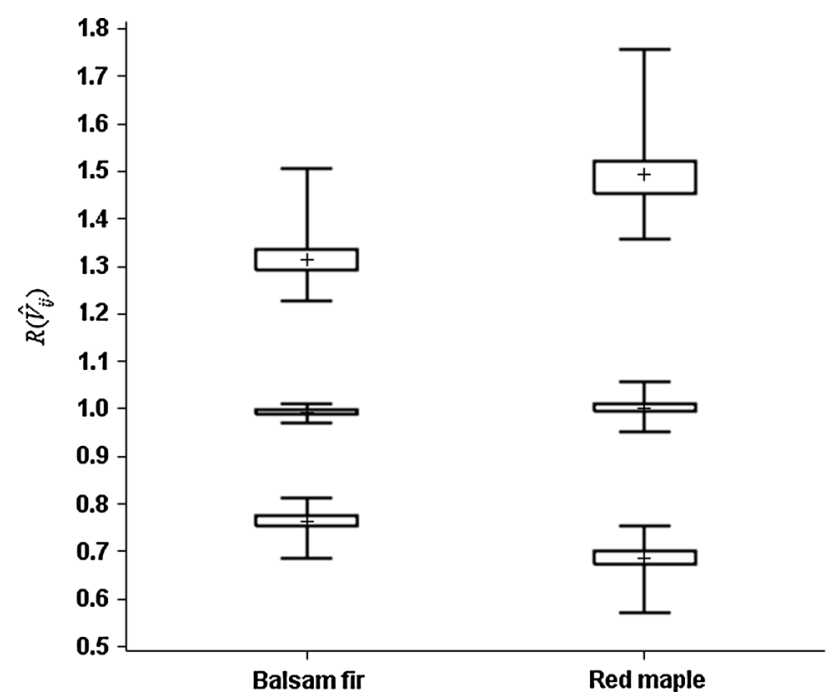

Fig. 4 Distributions of maximum, mean, and minimum volume ratios, $R\left(\hat{V}_{i j}\right)=\hat{V}_{i j}^{\sim} / \hat{V}_{i j}^{*}$, for 5000 replications by species
2010) that does not use upper-stem diameter information showed contrasting results between the two study species. For red maple, the population estimate based on the WS model was $2.2 \%$ larger and the standard error $1.7 \%$ larger than the corresponding estimates based on Clark et al. models (Table 5). The WS-based population estimate and standard error for balsam fir were 1.5 and $0.9 \%$ smaller, respectively, than those obtained with the Clark et al. models. The WS estimates were well within the $95 \%$ confidence intervals based on the Clark et al. models (Fig. 5). With the exclusion of one balsam fir and two red maple trees having abnormally high rates of taper in the lower bole, the ratio of tree volume predicted from the WS model to the volume predicted from Clark et al. ranged from 0.66 to 1.39 for red maple, with balsam fir having volume ratios between 0.69 and 1.07 (Fig. 6). There was a tendency for the WS model to predict smaller volumes than Clark et al. for balsam fir trees near the minimum dbh $(12.7 \mathrm{~cm})$. The trees having small ratios tended to be small trees for which the relative actual differences in cubic volume were also small, e.g., a WS volume of $0.008 \mathrm{~m}^{3}$ and a ratio of 0.7 imply the Clark et al. volume was $0.011 \mathrm{~m}^{3}$. The mean tree volume was approximately $0.12 \mathrm{~m}^{3}$.

\section{Discussion}

In terms of additional uncertainty associated with the diameter at $5.27 \mathrm{~m}$, it was clear that field measurements were preferable to model predictions when the field measurements had systematic measurement deviations that were zero or very small. However, the use of unbiased model predictions was generally favored if systematic field measurement deviations exceeded $\pm 0.1 \mathrm{~cm}$ for red maple or $\pm 0.2 \mathrm{~cm}$ for balsam fir (Table 3 ). Given the values of $\bar{D}$ reported in Table 1, it is not an obvious decision whether measured or predicted diameters are preferred. Factors to consider when contemplating which method to implement include: (1) there is often a tendency to be over-optimistic in the accuracy of field measurements, (2) field measurement time versus model development costs, and (3) the practical ability to effectively minimize uncertainty associated with field measurements and models. 
Table 5 Population estimates $\left(\hat{T}^{0}\right)$, standard errors $\left(S E^{0}\right)$, and summary statistics for individual-tree volumes $\left(\hat{V}_{i j}^{0}\right)$ using the taper models of Westfall and Scott (2010) and the percent differences in comparison with using the taper models of Clark et al. (1991)

\begin{tabular}{|c|c|c|c|c|c|c|c|}
\hline \multirow[t]{2}{*}{ Species } & \multirow[t]{2}{*}{$\hat{T}^{0}\left(\mathrm{~m}^{3}\right)$} & \multirow[t]{2}{*}{$S E^{0}$} & \multicolumn{3}{|c|}{$\hat{V}_{i j}^{0}\left(\mathrm{~m}^{3}\right)$} & \multirow[t]{2}{*}{$\% D_{(\hat{T})}$} & \multirow[t]{2}{*}{$\% D_{(\mathrm{SE})}$} \\
\hline & & & Min. & Mean & Max. & & \\
\hline Red maple & $2.7673 \mathrm{E}+08$ & 8778531 & 0.008 & 0.224 & 4.901 & 2.21 & 1.71 \\
\hline Balsam fir & $1.9219 \mathrm{E}+08$ & 5867771 & 0.007 & 0.117 & 1.395 & -1.47 & -0.86 \\
\hline
\end{tabular}

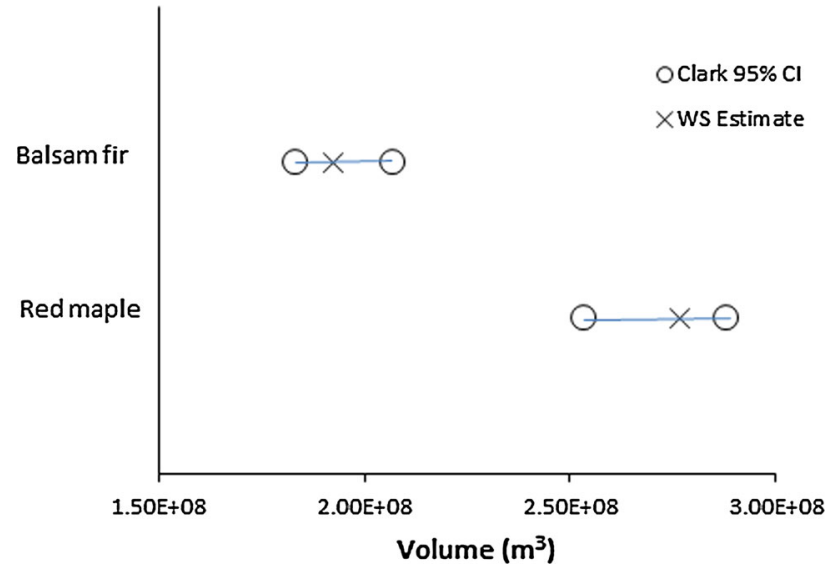

Fig. 5 Confidence intervals ( $95 \%$ ) for population estimates based on Clark et al. (1991) models and population estimates based on models of Westfall and Scott (2010), for balsam fir and red maple volume in Maine, USA

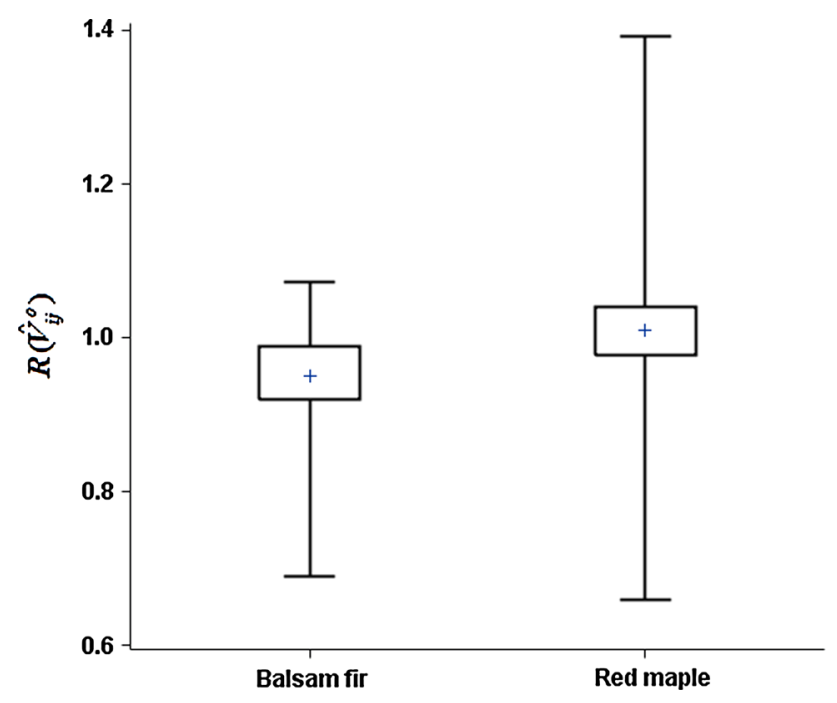

Fig. 6 Distribution of volume ratios, $R\left(\hat{V}_{i j}^{0}\right)=\hat{V}_{i j}^{0} / \hat{V}_{i j}^{*}$, between tree volumes predicted from Westfall and Scott (2010) and Clark et al. (1991) by species

In regard to factor $\# 1$, foresters often equate familiarity/experience with taking tree measurements as an indicator of accuracy. While there is undoubtedly some relationship, it may frequently be overestimated, e.g., the
Clutter et al. (1983) text referenced earlier. There is also empirical evidence that measurement quality objectives may be difficult to attain. Pollard et al. (2006) examined measurement repeatability for numerous attributes, where it was shown that tree height measurements to several merchantable top limits often failed to meet specified precision thresholds despite rigorous field crew training and certification requirements. Similarly, Kitahara et al. (2009) reported unexpectedly poor measurement quality for several forest inventory measurements, including diameter and height attributes. These publications in combination with other research finding the uncertainty of upper-stem diameter measurements to be relatively large (Berger et al. 2014; Williams et al. 1999; Fairweather 1994) suggest the value of using upper-stem diameter measurements is questionable.

Consideration of factor \#2 is dependent upon current circumstances, e.g., model development may be substantially less costly than taking field measurements if the data for model fitting are readily available. A desirable situation would be to have existing data of sufficient quality (e.g., felled-tree measurements) and population representation that model fitting is the only remaining task. A more realistic scenario entails either (1) the need to collect requisite high-quality data or (2) reliance on standing tree measures as is commonly found in inventory data. As shown in this analysis, the key to minimizing uncertainty due to model predictions relies on minimizing both parameter and residual uncertainty, which would presumably be enhanced by implementing option \#1 with a large sample size. However, option \#2 may be less costly financially but at the statistical expense of increased model prediction uncertainty. Of course, the costs associated with adoption of a modeling framework should be evaluated in relation to the advantages/disadvantages of taking the field measurements on individual trees, as this study indicated smaller uncertainty as compared to models as long as the measurements had minimal systematic deviation.

Factor \#3 is perhaps the most important consideration as it focuses on what can practically be attained to minimize uncertainty. For field measurements, the key components are the variability of measurements as well as the ability to 
ensure systematic deviation $\approx 0$. In this study, we estimated the measurement variability using data collected by well-trained field personnel. It may be that the variability is larger or smaller in other field data collection efforts. A more difficult problem is addressing potential systematic measurement deviation. The results suggested that such deviations in field measurements must be $\pm 0.2 \mathrm{~cm}$ or less to favor field measurements over unbiased models. Ensuring this standard is attained likely requires very careful (and therefore time-consuming/costly) measurements. Alternatively, addressing uncertainty in a prediction model often requires large datasets to effectively reduce the model parameter uncertainty. The data used to fit model (8) in this analysis came from a tree taper study that measured standing trees using a Barr \& Stroud dendrometer. Sample sizes were approximately 100 trees per species. The realized model uncertainty in other situations could be larger (less measurement accuracy and/or smaller sample sizes) or smaller (increased measurement accuracy and/or increased sample sizes) depending on the level of effort undertaken to obtain the data. Consequently, forest managers need to consider the practical realities of what their organization can attain with respect to minimizing measurement versus model uncertainty.

Numerous research studies have shown that more accurate individual-tree volume predictions are obtained when using an upper-stem diameter measurement in comparison with not using such information, but the degree of improvement is often small to moderate (Kozak 1998; Sabatia and Burkhart 2015; Cao and Wang 2015). Thus, the value of this increased accuracy needs to be assessed in context to the information needs. In cases where individual-tree volume estimates are important (e.g., high-value trees in timber sales), the use of upper-stem diameter measures could be of considerable benefit. In contrast, if population estimates are the primary interest then models that do not use upper-stem information may be suitable. This study showed that very similar population estimates were obtained using the models of either Clark et al. (1991) or Westfall and Scott (2010). The latter model formulation likely produces individual-tree volume predictions that are less accurate than the former, but also are not subject to the additional uncertainty of upper-stem measurements. Thus, in some cases the population estimates based on simpler taper models can be more precise than those obtained by more complex models.

This analysis focused on a specific height target $(5.27 \mathrm{~m})$ for the upper-stem measurement, which has generally been found to be one of the most effective measurements for improving estimates of total stem volume (e.g., Clark et al. 1991). Previous studies have also suggested that upper-stem measurements at $40-50 \%$ of total tree height are also quite effective at improving predictions (Kozak 1998; Sabatia and Burkhart 2015). In addition, measurements are also often taken much higher on the bole to address various merchantability standards. However, it is suspected that the uncertainty would greatly increase as the height of the measurement point increases, largely due to increased distance between the observer and the measurement point and possible sighting issues associated with crown characteristics. Because this hypothesis has not been tested, a more comprehensive assessment of upper-stem diameter uncertainty is warranted to ascertain properties at various measurement heights other than $5.27 \mathrm{~m}$. A broader analysis would be more complex as height of the upper-stem measurement, diameter of the upper-stem measurement, and crown effects would likely need to be considered as inter-related factors.

\section{Conclusion}

Although it is common to consider forestry data as observed without uncertainty, considerable variability can be present which, when ignored, leads to overly optimistic confidence in results. This occurs for both measured and predicted variables that are found in forestry databases. In this study, the use of both measured and predicted values was assessed in the context of tree volume prediction to ascertain whether one method should be preferred. The results suggested that, from a minimum mean squared error perspective, measured upper-stem diameter is preferred when no systematic deviation is present; however, even small amounts of measurement deviation can tip the scales in favor of using unbiased model predictions instead of field measurements. Given the accuracy and precision of measurements and model predictions are highly dependent on numerous factors particular to a given situation, the results shown here should not be construed to apply in all settings; rather, similar analyses should be undertaken in the context of the specific activity being conducted.

The uncertainty associated with the measurement of diameter at $5.27 \mathrm{~m}$ was estimated using several data sources. These data sources represent a specific combination of measurement protocols, field crew experience/expertise, environmental conditions, and tree growth forms. Thus, efforts using other data sources may produce differing outcomes; however, the results serve as indicators of the magnitude of uncertainty likely to be encountered. Also of considerable importance is understanding the drivers of uncertainty for both measured and predicted data and assessing the practical ability to effectively minimize the underlying causes. Evaluation of the findings presented in this study will assist forest managers in determining appropriate courses of action for their information needs and intended outputs. 


\section{References}

Berger A, Gschwantner T, McRoberts RE, Schadauer K (2014) Effects of measurement errors on individual tree stem volume estimates for the Austrian National Forest Inventory. For Sci 60:14-24

Breidenbach J, Antón-Fernández C, Petersson H, McRoberts RE, Astrup R (2014) Quantifying the model-related variability of biomass stock and change estimates in the Norwegian National Forest Inventory. For Sci 60:25-33

Cao QV, Wang J (2015) Evaluation of methods for calibrating a tree taper equation. For Sci 61(2):213-219

Clark A III, Souter RA, Schlaegel BE (1991) Stem profile models for southern tree species. USDA For Serv Res Pap SE-282

Clutter JL, Fortson JC, Pienaar LV, Brister GH, Bailey RL (1983) Timber management: a quantitative approach. John Wiley \& Sons, Inc

Czaplewski RL, McClure JP (1988) Conditioning a segmented stem profile model for two diameter measurements. For Sci 34(2):512-522

Fairweather SE (1994) Field tests of the criterion 400 for hardwood tree diameter measurements. North J Appl For 11(1):29-31

Homer C, Huang C, Yang L, Wylie B, Coan M (2004) Development of a 2001 national landcover database for the United States. Photogramm Eng Remote Sens 70:829-840

Jordan L, Berenhaut K, Souter R, Daniels RF (2005) Parsimonious and completely compatible taper, total, and merchantable volume models. For Sci 51:578-584

Kalliovirta J, Laasasenaho J, Kangas A (2004) Evaluation of the laser-relascope. For Ecol Manag 204(2-3):181-194

Kitahara F, Mizoue N, Yoshida S (2009) Evaluation of data quality in Japanese National Forest Inventory. Environ Monit Assess 159:331-340

Kozak A (1998) Effects of upper stem measurements on the predictive ability of a variable-exponent taper equation. Can J For Res 28:1078-1083

Li R, Weiskittel AR (2010) Comparison of model forms for estimating stem taper and volume in the primary conifer species of the North American Acadian Region. Ann For Sci. doi:10. 1051/forest/2009109

McRoberts RE, Westfall JA (2014) Effects of uncertainty in model predictions of individual tree volume on large area volume estimates. For Sci 60(1):34-42

McRoberts RE, Hahn JT, Hefty GJ, Van Cleve JR (1994) Variation in forest inventory measurements. Can J For Res 24:1766-1770

McRoberts RE, Moser P, Zimermann LZ, Vibrans AC (2015) A general method for assessing the effects of uncertainty in individual-tree volume model predictions on large-area volume estimates with a subtropical forest illustration. Can J For Res 45(1):44-51

Pollard JE, Westfall JA, Patterson PL, Gartner DL, Hansen M, Kuegler O (2006) Forest inventory and analysis national data quality assessment report for 2000 to 2003. USDA For Serv Gen Tech Rep RMRS-GTR-181

Sabatia CO, Burkhart HE (2015) On the use of upper stem diameters to localize a segmented taper equation to new trees. For Sci $1(3): 411-423$

Scott CT (1981) Northeastern forest survey revised cubic-foot volume equations. USDA For Serv Res Note NE-304

Scott CT, Bechtold WA, Reams GA, Smith WD, Westfall JA, Hansen MH, Moisen GG (2005) Sample-based estimators used by the forest inventory and analysis national information management system. In: Bechtold WA, Patterson PL (eds) The enhanced forest inventory and analysis program-national sampling design and estimation procedures. USDA For Serv Gen Tech Rep SRS-80. pp 53-77

Shettles M, Temesgen H, Gray AN, Hilker T (2015) Comparison of uncertainty in per unit area estimates of aboveground biomass for two selected model sets. For Ecol Manag 354:18-25

Trincado G, Burkhart HE (2006) A generalized approach for modeling and localizing stem profile curves. For Sci 52:670-682

US Forest Service (2006) National core field guide (Northern edition): Version 3.1. Vol 1: field data collection procedures for phase 2 plots. http://www.nrs.fs.fed.us/fia/data-collection/field-guides/ Final_NRS_ver_3-1_10_2006_corrected.pdf. Accessed 6 April 2016

Weaver SA, Ucar Z, Bettinger P, Merry K, Faw K, Cieszewski CJ (2015) Assessing the accuracy of tree diameter measurements collected at a distance. Croat J For Eng 36(1):73-83

Westfall JA, Scott CT (2010) Taper models for commercial tree species in the northeastern United States. For Sci 56(6):515-528

Westfall JA, Patterson PL, Coulston JW (2011) Post-stratified estimation: within-strata and total sample size recommendations. Can J For Res 41:1130-1139

Westfall JA, MacFarlane DW, Weiskittel AR (2012) Biomass measurement and modeling challenges for hardwood species in the northern region. In: Morin RS, Liknes GC (comps) Moving from status to trends: Forest Inventory and Analysis (FIA) symposium 2012. USDA For Serv Gen Tech Rep NRS-P-105 pp 357-360

Williams MS, Cormier KL, Briggs RG, Martinez DL (1999) Evaluation of the Barr \& Stroud FP15 and Criterion 400 laser dendrometers for measuring upper stem diameters and heights. For Sci 45(1):53-61 